\title{
Currículo e Trabalho Docente no Curso de Ciências Contábeis
}

\author{
Curriculum and Teaching Job Course of Accounting Sciences \\ Marcos Laffin \\ marcoslaffin@gmail.com \\ UFSC
}

\begin{abstract}
Resumo
Este estudo teve como objetivo compreender os fundamentos epistemológicos da organização do trabalho do professor de contabilidade no ensino superior. Para tanto, caracteriza-se a sua trajetória de formação e inserção no trabalho docente, assim como foram identificadas as concepções epistemológicas e categorias metodológicas do trabalho no ensino superior de Ciências Contábeis. A questão central sobre o trabalho do professor buscou caracterizar quais são os componentes epistemológicos do processo de ensino que organizam o trabalho do professor de contabilidade no ensino superior. Para responder a essa questão decidiu-se pela abordagem qualitativa, mediante a qual se escolheu como referência os princípios explicativos de Homem e Trabalho. Por meio desse eixo teórico é enfatizada a constituição do sujeito e a sua condição humana através de suas relações sociais, históricas e culturais, declarando assim sua possibilidade omnilateral. Ao concluir esse estudo, afirma-se que ensinar exige responsabilidade porque, para além do domínio de conteúdos específicos e de saberes de formação humana, assim como de métodos adequados a promover essas apropriações no contexto no qual está inserido, é preciso insistir na solidariedade humana, na preservação do mundo humano. Essa sensibilidade coletiva será visível nas atividades do professor de contabilidade quando, em seu trabalho, configurar-se um entendimento crítico e emancipatório da categoria trabalho.
\end{abstract}

Palavras-chave: Ensino Superior. Professor de Contabilidade. Currículo e Trabalho Docente.

\begin{abstract}
This study aimed to understand the epistemological foundations of the organization of the work of a professor of accounting in higher education. Therefore, characterized his trajectory and insertion training in teaching, as well as identified the epistemological concepts and categories of methodological work in higher education of Accountancy. A central question about the teacher's work sought to characterize what are the epistemological components of teaching that organize the work of a professor of accounting in higher education. To answer this question it was decided by the qualitative approach, which is chosen by reference to the explanatory principles of Human and Labour. Through this theoretical axis is emphasized the constitution of the subject and the human condition through their social, historical and cultural, thus declaring its possibility omnilateral. Upon completion of this study, it is argued that teaching requires responsibility because, beyond the specific content and domain knowledge of human development, as well as appropriate methods to promote these appropriations in the context in which it is inserted, we must insist on human solidarity, the preservation of the human world. This collective sensibility is visible in the activities of the
\end{abstract}


accounting professor when, in his work, setting up a critical understanding of the category and emancipatory work.

Keywords: Higher Education. Professor of Accounting. Curriculum and Teaching Work.

Artigo recebido em: 18.10.2012; Aceito em: 28.12.2012

\title{
INTRODUÇÃO
}

\begin{abstract}
O ser humano é a um só tempo físico, biológico, psíquico, cultural, social, histórico. Esta unidade complexa da natureza humana é totalmente desintegrada na educação por meio das disciplinas, tendo-se tornado impossível aprender o que significa ser humano. É preciso restaurá-la, de modo que cada um, onde quer que se encontre, tome conhecimento e consciência, ao mesmo tempo, de sua identidade complexa e de sua identidade comum a todos os outros humanos (MORIN, 2000, p.15).
\end{abstract}

O contexto sócio-político-econômico e cultural no qual a sociedade contemporânea assenta suas ações encontra-se complexificado de incertezas e de provisoriedades em face da emergência de novos conhecimentos e novos procedimentos do homem, os quais se intensificam e acabam por afetar o conjunto da sociedade humana. No conjunto complexo das relações humanas é preciso ressignificar o ser humano em sua condição humana para que, no contexto da sua condição, seja possível enfrentar o desafio que se coloca a todas as instituições, ao mesmo tempo em que se coloca a todos os seres humanos.

Ao se requerer do profissional da contabilidade um entendimento amplo do contexto social em que se insere, bem como da concepção de mundo que assume na produção de seu trabalho, faz-se necessário instrumentalizá-lo nas condições concretas de sua existência. Por conseguinte, ao articular o conjunto dessas relações e ao compreender tais condições, o profissional da contabilidade poderá realizar nas múltiplas dimensões do seu trabalho o processo inesgotável de constituição do humano também como sujeito histórico.

O processo de apropriação e construção de novos conhecimentos para desenvolver novas práticas sociais tem evidenciado a discussão do tema da formação nas mais diferentes áreas da produção humana. Os procedimentos de especialização para alguns tipos de trabalho têm se constituído como indispensáveis para o exercício da atividade e se configurado como formação continuada.

No âmbito do ensino superior de Ciências Contábeis, a Resolução que institui as Diretrizes Curriculares Nacionais do Curso de Graduação em Ciências Contábeis, em discussão desde 1997, foi homologada pela Resolução CES/CNE no 10/2004. De maneira geral o currículo do curso, estabelecido pela referida Resolução, está organizado predominantemente com as contribuições dos conhecimentos das ciências socioeconômicas, assim, os problemas mais amplos do mundo real são sublimados, ficando circunscritos à reflexão e à resolução de problemas somente no que se refere aos aspectos imediatos à organização, fato que tem contribuído para inibir a reflexão da ação no cotidiano da atividade de ensino, não favorecendo a articulação desses conhecimentos com o conjunto das relações sociais. As questões didático-pedagógicas, como preocupações teórico-práticas que possibilitam a reflexão das ações do dia a dia no processo ensino-aprendizagem, ainda não são tomadas 
como fundamentais nesta área de ensino. Neste contexto, as teorias da educação, assim como as contribuições da sociologia, da psicologia e da filosofia apresentam-se como descoladas da realidade da formação do professor de contabilidade. Este fato, constatado nesta pesquisa, indica, ainda, que a percepção de mundo, de sujeito e do fenômeno educativo fique restrita ao conjunto dos limites de sua formação técnica. As contribuições das ciências humanas são vistas por estes, na maioria das vezes, de forma desintegrada da análise dos fenômenos sociais, inibindo assim, avanços na formação do profissional da área contábil.

Nas últimas décadas, marcadas, sobretudo pela internacionalização da economia, as organizações estão restringindo a ocupação de cargos e funções à formação especializada, exigindo diferentes saberes para as mais diversas atividades. Mediante essas constatações, neste texto, ao discutir a formação do professor de contabilidade, pretende-se contribuir com as discussões na área do ensino da contabilidade, entendendo-o como referência entre a nova base da realidade social e as exigências de profissionais especializados para atuarem na gestão dos negócios da organização, assim como na operacionalização da produção de bens e serviços.

Em nossa cultura, a formação e a especialização do bacharel em ciências contábeis são certificadas pelo processo de escolarização. Assim, ao educar o cidadão, princípio primeiro da universidade, esta deveria nortear também as relações de proximidade entre as necessidades do contexto social e a construção de conhecimentos para práticas sociais de inclusão. No entanto, a inter-relação entre educação e trabalho na área da contabilidade muitas vezes tem se restringido à transmissão dos conhecimentos contábeis com ênfase no tecnicismo associado aos conteúdos mecanicistas, moldando a formação do profissional da contabilidade nos moldes da racionalidade técnica.

Refletir sobre o trabalho do professor de contabilidade como atividade social implica o comprometimento com a melhoria desse nível de ensino. Requer, ainda, reconhecer o percurso dessa formação visando contribuir para uma trajetória de vida pessoal e profissional que identifique o professor como sujeito de saberes que o constitua pelo estatuto da profissão de professor, compreendendo-se como sujeito de intervenção e, dialeticamente, como capaz de repensar-se e de refazer-se, o que é próprio da incompletude da condição humana, na parcialidade dos seus saberes.

A formação do professor de contabilidade implica, portanto, a dimensão e a proposição de práticas pedagógicas com caráter inovador que permitam a apropriação do seu trabalho por meio da reflexão das suas ações. Reflexão que possibilitará a reconstituição de teorias e práticas, associando-as aos procedimentos de crítica, criatividade e autonomia na apreensão da realidade circundante, para a promoção de uma educação entendida como prática social no contexto dos arranjos sociais que se efetivam. Não se cogita o afastamento da formação técnica específica; pelo contrário, supõe-se ampliar a esses fundamentos um referencial mais amplo para a formação do contador. Logo, discutir a formação do professor de contabilidade implica detectar os atuais problemas nos quais o conhecimento contábil exerce fator de responsabilidade social como participante na busca de alternativas. Segundo Sacristán (1995),

"A discussão sobre a profissionalidade do professor é parte integrante do debate sobre os fins e as práticas do sistema escolar, remetendo para o tipo de desempenho e de conhecimentos específicos da profissão docente (SACRISTÁN, 1995, p.65). 
Assim, a formação do professor de contabilidade deverá articular o que é próprio da função docente com a realidade do trabalho da contabilidade, possibilitando que situações de trabalho se convertam simultaneamente em situações de formação. Tais articulações deverão tornar possível a extensão das dimensões da gestão do conhecimento contábil para abranger as mudanças que ocorrem em contextos históricos. A seguir são apresentadas algumas discussões e questões que emergiram na pesquisa que teve como objetivo identificar a inserção do contador e suas concepções sobre o trabalho que desenvolve como professor de contabilidade no ensino superior.

\section{ALGUMAS CONFIGURAÇÕES DO CURRÍCULO NO TRABALHO DO PROFESSOR DE CONTABILIDADE}

De acordo com a descrição e análise dos componentes da organização do trabalho do professor de contabilidade, elaborada a partir do questionário e dos depoimentos, é apresentado a seguir um quadro-síntese de como o currículo e demais componentes pedagógicos se configuram na organização do trabalho do professor, assim como as suas reivindicações.

Quadro1: Componentes da Organização do Trabalho do Professor de Contabilidade

\begin{tabular}{|c|c|}
\hline Componentes - como ocorre & Componentes - reivindicações \\
\hline A aula é a organização do Trabalho docente & - \\
\hline $\begin{array}{l}\text { Prescrições Curriculares } \\
\text { Essência da organização }\end{array}$ & $\begin{array}{l}\text { Articulação vertical e horizontal entre } \\
\text { disciplinas }\end{array}$ \\
\hline $\begin{array}{c}\text { Concepção de ensino-aprendizagem } \\
\text { Transmissão-assimilação } \\
\end{array}$ & - \\
\hline $\begin{array}{c}\text { Tempo e Ritmo } \\
\text { Enfase na seqüência curricular }\end{array}$ & - \\
\hline $\begin{array}{c}\text { Saberes específicos atuais } \\
\text { Abordagem de forma superficial }\end{array}$ & Seminários de Integração Pedagógica \\
\hline $\begin{array}{l}\text { Estratégias para assimilação e motivação } \\
\text { Trabalho em grupo, seminários, exercícios práticos }\end{array}$ & ( \\
\hline Disciplina como parte do currículo & Projeto Político-Pedagógico \\
\hline Perfil do aluno & - \\
\hline $\begin{array}{c}\text { Seleção de conteúdos } \\
\text { Ementa, Programa oficial, Provão, mercado }\end{array}$ & $\begin{array}{c}\text { Concepção mais ampla do conhecimento e } \\
\text { da socialização }\end{array}$ \\
\hline $\begin{array}{c}\text { Ensino e Pesquisa } \\
\text { Como atividades complementares }\end{array}$ & Condições de Trabalho \\
\hline $\begin{array}{c}\text { Trabalho coletivo } \\
\text { Institucionais e informais - pública / Informais - } \\
\text { particular }\end{array}$ & Críticas à organização universitária \\
\hline
\end{tabular}

Fonte: Dados da pesquisa (2012)

Os componentes da organização do trabalho do professor de contabilidade no ensino superior envolvem concepções do processo ensino-aprendizagem, do aluno, da avaliação, da instituição universitária, do ser professor, os quais conjugados, constituem, caracterizam e formatam um determinado currículo.

Os estudos realizados por Sacristán (1998, p.101) sobre as práticas de ensino e seus componentes permitem inferir que o currículo como ligação de múltiplos agentes produz em suas margens um espaço para produzir ações que configuram a sua própria estrutura. A 
compreensão do currículo como um núcleo que se constrói a partir de diferentes agentes e de ações, ao mesmo tempo que requer um tipo de intervenção explicitamente atuante das decisões dos professores, implica aceitar o currículo como construção temporal.

Segundo Sacristán,

O currículo é muitas coisas ao mesmo tempo: idéias pedagógicas, estruturação de conteúdos de uma forma particular, detalhamento dos mesmos, reflexo de aspirações educativas mais difíceis de moldar em termos concretos, estímulo de habilidades nos alunos, etc. Ao desenvolver uma prática concreta de modo coerente com quaisquer desses propósitos, o professor desempenha um papel decisivo (SACRISTÁN, 1998, p. 173).

Nesse entendimento, a construção do currículo é também processual e seu desenvolvimento é suscetível a enfoques paradigmáticos. O ensino superior de contabilidade que pretende formar um profissional crítico e um cidadão capaz de intervenções deverá integrar simultaneamente práticas pedagógicas aos conteúdos curriculares de formação específica, visando não apenas à melhoria na formação profissional, mas simultaneamente à melhoria nas relações humanas estabelecidas pela condição humana.

O professor de contabilidade do ensino superior, ao ter e assumir uma maneira prescrita de organizar o trabalho, não demonstra compreensão das possibilidades do seu trabalho como ações de responsabilidade com a contínua e necessária formação profissional, como também não relativiza a dinâmica dos conhecimentos e sua socialização para a apreensão da singularidade do trabalho docente. A trajetória de inserção e de formação do professor de contabilidade do ensino superior caracterizada pelos professores pesquisados, assim como suas práticas pedagógicas decorrentes desse mesmo processo de inserção e formação não pode justificar nem representar, sob pena de completa alienação, o imobilismo frente ao trabalho produzido. Há que se inferir que o produto do trabalho do professor de contabilidade difere substancialmente do produto do trabalho do contador. Nesse sentido, compreender e realizar o trabalho docente como atividade intencional, que se coloca como espaço de lutas e de conflitos para apreender e constituir novas possibilidades requer a compreensão do que seja o currículo, da sua objetivação e das implicações teórico-metodológicas que uma determinada opção curricular impõe.

Segundo Kuenzer (1992),

“ [...] a relação com o mundo do trabalho não pode mais ser concebida como um momento separado na proposta curricular. Ao contrário, deverá ser parte integrante de toda proposta, estando presente em todos os conteúdos através de ações que incorporem o estado atual da discussão da relação entre ciência e trabalho em cada momento do currículo, de modo a manter uma estreita relação entre teoria e prática." (KUENZER, 1992, p. 16)

É, sobretudo, no currículo do curso de Ciências Contábeis que requer estreita vinculação entre teoria e prática na tentativa de superar a racionalidade instrumental, que o trabalho do professor precisa incorporar as diferentes demandas das dimensões humanas tanto quanto dos conhecimentos profissionais que ajuda a reelaborar. É nesta concepção de prática pedagógica que podemos compreender as contribuições de Sacristán (1998), que caracteriza a objetivação do currículo no processo de seu desenvolvimento e sugere formas de compreender e interferir intencionalmente na constituição do currículo. O domínio das formas de objetivação do currículo favorece a mediação pedagógica, como ações socialmente partilhadas por 
professores comprometidos com a educação, entendida em dimensões complexas e, portanto, requer professores capazes de leiturizar e intervir em contextos tão desiguais.

Segundo Sacristán (1998, 104-106), a objetivação do currículo pode ser compreendida em seus diferentes níveis, a saber:

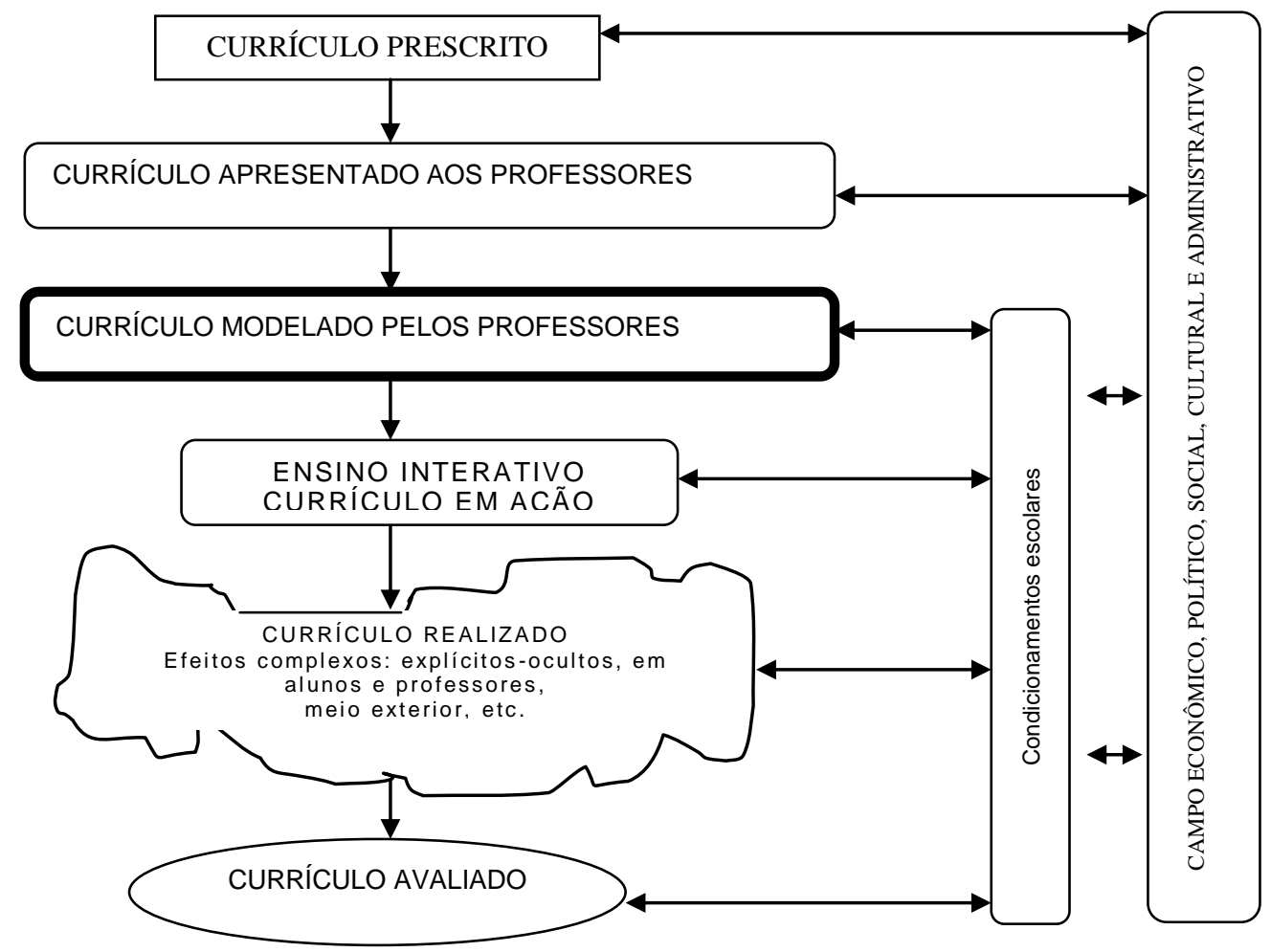

Figura1: A objetivação do currículo no processo de seu desenvolvimento.

Fonte: SACRISTÁN, J. Gimeno. O Currículo - Uma reflexão sobre a prática. Porto Alegre, RS: ARTMED, 1998: 105.

De acordo com a perspectiva proposta por Sacristán, pode-se inferir que os diferentes níveis de compreensão e domínio do currículo se assumem como ancoragem fundamental no processo de formação do profissional da área contábil. Os problemas referentes ao não domínio dos componentes que organizam o trabalho do professor de contabilidade principiam não apenas porque as práticas pedagógicas derivam de uma proposta prescrita e depois são modeladas pelos professores, mas porque, fundamentalmente, integralizam-se práticas de ensino e conhecimentos específicos derivados de saberes individuais. Contudo, se as práticas pedagógicas, como componentes do currículo, são ações selecionadas para lidar também com os conteúdos, essas não devem se sobrepor aos próprios conteúdos, em função de que acabam deslocando a importância do ensino para as ações didáticas em detrimento da aprendizagem dos conteúdos. Porém, a presença do professor no âmbito do ensino da contabilidade é assimilada na maioria das práticas muito mais pelos recursos que são utilizados na organização do seu trabalho do que pela mediação dos conteúdos no processo ensinoaprendizagem. Nesse contexto, refletir a prática pedagógica, implica compreender que os recursos didáticos utilizados são instrumentos de mediação, tanto físicos quanto simbólicos, no processo de ensino-aprendizagem e possibilita apreender os conteúdos curriculares como possibilidades de construção conceitual de saberes que, ampliados, contribuiriam para a 
constituição crítica dos sujeitos e das diferentes formas de apropriação de sua condição humana. No entanto, essa forma de compreender o currículo ainda não se faz presente no ensino superior de contabilidade.

No currículo modelado pelos professores de contabilidade aliam-se diferentes conhecimentos e atividades no desenvolvimento do processo ensino-aprendizagem. Aliam-se não apenas os conteúdos contábeis recortados curricularmente, mas também as experiências profissionais do professor e sua trajetória de vida. Ao modelar o currículo, o professor acaba por configurar certa autonomia e participação no trabalho pedagógico que, como se viu, muitas vezes podem produzir efeitos complexos que irão interferir não apenas na aprendizagem dos alunos, mas também nas formas de compreender a própria atividade docente. No entanto, conhecer e dominar os conteúdos da área curricular de atuação é função imprescindível do professor que apreendeu o ensino como categoria do trabalho apropriado.

Se o professor de contabilidade conhece e domina os conteúdos contábeis com os quais ensina, terá condições de articular conteúdos básicos aos conteúdos que demandam processos de mediação mais elaborados, os quais possibilitarão sua autonomia e participação no ensino, não pela fragmentação do currículo, mas pela modelagem de um currículo plenamente compreendido e contextualizado.

Nessa forma de compreender o currículo, a ordenação e sequenciação não-linear de conteúdos não se configuram em mera disposição curricular, mas antes considera também os diferentes componentes da organização do trabalho docente para que o aluno signifique sua aprendizagem como processo em construção, tanto quanto o professor. Nessa perspectiva, a significação do aluno em suas aprendizagens tende a superar a aprendizagem mecânica atribuindo significado à mediação do professor em suas diferentes atividades e intervenções.

A situação problemática e identificada na pesquisa reside em que a grande maioria dos professores de contabilidade pesquisados não teve acesso, em seu processo de formação, a uma sólida formação contábil, nenhuma formação específica para a atividade docente e tampouco a uma sólida formação filosófica que possibilite contrapor-se intencionalmente ao modelo capitalista excludente, para que tenha como entendimento que o currículo é um artefato cultural construído historicamente e, portanto, plenamente possível de reelaborações. $\mathrm{Na}$ ausência dessas mediações, a intervenção política sobre o currículo se fragiliza, dando continuidade, muitas vezes, a ações que não se constituem em práticas pedagógicas, mas sim em formas simplificadas de executar o currículo prescrito. Nesse aspecto, a educação contábil de qualidade que se pretende para todos, deverá se constituir em eixo norteador para superar as atuais condições do trabalho do professor de contabilidade do ensino superior e da profissão contábil, sob o risco de assumir-se a retórica do discurso para repetidamente justificar o ensino superior de contabilidade, também, como lugar de exclusão.

\section{CONCLUSÕES}

Com base na pesquisa empírica foi delineado o perfil dos (28) vinte e oito professores de contabilidade que se disponibilizaram a participar desse estudo. A identificação de sua formação e das formas de inserção no trabalho docente permitiu melhor compreender a dupla cidadania que se funda entre ser professor e ser contador. Essa ambigüidade estável e ao mesmo tempo marginal indiciou os significados atribuídos ao trabalho no ensino superior de contabilidade, mediante os quais emerge o discurso de que o contador ajuda a formar o professor de contabilidade.

R. Cont. Ufba, Salvador-Ba, v. 6, n. 3, p. 66-77, setembro-dezembro 2012 
Rever cuidadosamente os dados sobre a prática da docência do ensino superior de contabilidade, não como um privilégio particularizado, mas como prerrogativa para compreendê-lo na totalidade das demais informações e do contexto, possibilitou tornar visíveis as concepções epistemológicas que os professores de contabilidade pesquisados têm sobre os componentes do processo ensino-aprendizagem. A concepção identificada, marcadamente instrumental, conjuga-se e incorpora-se aos componentes da organização do trabalho do professor de contabilidade e ficaram assim delineados:

Quadro 2. Concepção dos Componentes Pedagógicos

\begin{tabular}{|c|c|}
\hline $\begin{array}{c}\text { Componentes epistemológicos do processo ensino- } \\
\text { aprendizagem }\end{array}$ & $\begin{array}{c}\text { Na organização do trabalho do professor de } \\
\text { contabilidade no ensino superior }\end{array}$ \\
\hline $\begin{array}{l}\text { Ao compreender o aluno como um sujeito } \\
\text { inato, o homem pronto e acabado, acredita } \\
\text { que está no aluno o desenvolvimento de suas } \\
\text { competências e habilidades. }\end{array}$ & $\begin{array}{l}\text { Por isso, o aluno deverá ter um perfil e gosto } \\
\text { pela contabilidade, sem os quais, o que resta } \\
\text { ao aluno é um processo de recuperação dos } \\
\text { conteúdos nas atividades prescritas. }\end{array}$ \\
\hline $\begin{array}{c}\text { Ao ensinar na concepção da } \\
\text { transmissão/assimilação, sua expectativa do } \\
\text { ensino configura-se nas respostas previsíveis } \\
\text { e emitidas pelo aluno. }\end{array}$ & $\begin{array}{l}\text { Diante desse entendimento, o ensino é } \\
\text { organizado pelo saber do professor. O } \\
\text { conhecimento contábil revela-se endógeno e, } \\
\text { assim, é reproduzido, ao mesmo tempo que } \\
\text { não é questionado, indica a ausência da } \\
\text { pesquisa como procedimento no ensino. }\end{array}$ \\
\hline $\begin{array}{l}\text { A aprendizagem ocorre quando são visíveis } \\
\text { as mudanças de comportamento, } \\
\text { principalmente aquelas associadas à vocação } \\
\text { contábil. }\end{array}$ & $\begin{array}{l}\text { As estratégias para assimilação e motivação } \\
\text { da aprendizagem são realizadas em trabalhos } \\
\text { de equipe, seminários e exercícios, sendo } \\
\text { centralizados pela avaliação somatória e } \\
\text { classificatória. }\end{array}$ \\
\hline $\begin{array}{l}\text { O professor é o contador técnico- } \\
\text { especialista. A sua trajetória não contempla } \\
\text { uma formação pedagógica e uma vivência } \\
\text { acadêmica. }\end{array}$ & $\begin{array}{l}\text { A aula é a organização do trabalho do } \\
\text { professor. A disciplina com a qual trabalha é } \\
\text { individualizada no currículo. Os saberes } \\
\text { específicos atuais são marginalizados. }\end{array}$ \\
\hline $\begin{array}{l}\text { A metodologia é compreendida como sendo } \\
\text { os recursos e os meios com primazia na } \\
\text { exposição do professor, centralizando as } \\
\text { atividades em exercícios e repetições. }\end{array}$ & $\begin{array}{c}\text { Teoria e prática confundem-se. Os } \\
\text { exercícios e trabalhos realizados na aula são } \\
\text { entendidos como o exercício da prática } \\
\text { contábil. }\end{array}$ \\
\hline $\begin{array}{c}\text { A avaliação organiza o ensino e serve para } \\
\text { medir a aprendizagem. É enfatizada a } \\
\text { memorização, convergindo-se para a } \\
\text { repetição de atividades para recuperar } \\
\text { rendimentos. }\end{array}$ & $\begin{array}{c}\text { Tempo e ritmos diferentes são percebidos, } \\
\text { mas subestimados pela ênfase conteudista. A } \\
\text { abordagem do programa curricular é } \\
\text { quantitativa. }\end{array}$ \\
\hline $\begin{array}{c}\text { O currículo significa que o aluno vem para o } \\
\text { curso para ser contador. }\end{array}$ & $\begin{array}{c}\text { A organização da aula é baseada nas } \\
\text { prescrições das ementas e o programa de } \\
\text { cada disciplina é a essência da organização } \\
\text { da aula. A seleção de conteúdos representa a } \\
\text { concepção que os professores têm do } \\
\text { currículo. }\end{array}$ \\
\hline $\begin{array}{l}\text { A universidade é a instância formal do } \\
\text { conhecimento. }\end{array}$ & $\begin{array}{c}\text { O ensino e a pesquisa estão vinculados às } \\
\text { condições de trabalho. A pesquisa, quando } \\
\text { ocorre, é confundida com assessoria ou como } \\
\text { extensão, e assim, é assumida como }\end{array}$ \\
\hline
\end{tabular}

R. Cont. Ufba, Salvador-Ba, v. 6, n. 3, p. 66-77, setembro-dezembro 2012 
complementar e não integrada. O trabalho individual e a ausência de trabalho coletivo decorrem das condições de trabalho.

Fonte: Dados da Pesquisa (2012)

Pode-se afirmar que na pesquisa realizada identificou-se que os professores de contabilidade gostam do que fazem. Necessário é discutir como esse gostar se expressa em suas concepções epistemológicas e destas, quais as consequiências na organização do seu trabalho para a constituição do aluno como humano omnilateral.

Verificou-se que o aluno, como ser humano não é percebido na sua complexa totalidade. É feito dele um recorte e espera-se desse recorte competências e habilidades sem, no entanto, provê-lo para a construção dessas relações. Esse entendimento da prontidão e do inatismo do ser humano, ao mesmo tempo que limita as possibilidades do aluno de se relacionar com o mundo, destitui o professor como sujeito de mediação nas relações com o mundo e com o saber contábil.

Desse modo, o professor muitas vezes tem dificuldade de perceber o produto de seu trabalho o processo ensino-aprendizagem -, porque esse produto não se materializa em algo palpável e imediato. Nessa perspectiva, a avaliação é algo que representa o imediato, que conclui o trabalho do professor e desse modo, restringe a aula como meio de seu trabalho.

Trabalho esse que não é percebido pelo professor como uma produção sua, mas como uma prescrição inalterável que apenas executa. Nessa compreensão, desaparece não apenas o processo de seu trabalho, como também o produto dele. Esse entendimento do trabalho como fim em si mesmo, trabalho utilitário, carrega também um entendimento de naturalização do ser humano, diferente, portanto, do entendimento de sua condição humana e histórica e das possibilidades da multidimensionalidade.

O professor, ao não distinguir a produção da aula como produção de conhecimento, e esse conhecimento, como instrumento de mediação para novas relações sociais, não se instrumentaliza na pesquisa porque a compreende como meio e fim de um processo de consumo que é conclusivo no aprender do aluno.

Outra questão a ser melhor compreendida pelos professores é saber diferenciar o professor de contabilidade dos demais usuários do conhecimento contábil pelo tipo de trabalho que realiza: o trabalho pedagógico. O formato que assumem as atividades do professor de contabilidade é diferente daquele realizado pelo contador. Enquanto para o contador existe uma rotina de normas e aspectos legais, de procedimentos para registro e controle do patrimônio administrado, de um resultado objetivado decorrente de atos e fatos administrativos do contexto específico das organizações, para o professor de contabilidade, além de toda essa formatação do trabalho, existe ainda o fato de que, ao lidar com a formação dos outros sujeitos está exercendo uma prática social permeada por suas concepções de ser humano e de sociedade, na qual ele precisa lidar com modos de pensar a aula, com a sua organização, com a seleção de saberes e com a reflexão constante de todo esse processo.

Refletir e apropriar-se do trabalho como dimensão humana e perceber as mudanças nas suas formas de ser no mundo contemporâneo implica ver e discutir as condições que o ser humano possui no modo vigente de produzir trabalho e, de outro lado, as formas de exclusão no seu modo de produzir-se humano.

Destaca-se como extremamente relevante a afirmação dos professores de que "trabalhar em contabilidade acrescenta muito ao ensino". Nesse sentido, vislumbra-se uma busca de 
articulação entre teoria e prática, entre a academia e o mundo das organizações empresariais. Mas é preciso, também, compreender que trabalhar no ensino não é pasteurizar conhecimentos produzidos historicamente em tempos e contextos diferentes.

Outra constatação refere-se ao status social que o contador encontra no exercício de ser professor. O ser professor é visto como possibilidade de amplitude de conhecimentos, já o ser contador permite melhor retribuição econômica, o que pode resultar no fato de não haver um investimento na carreira de ser professor e, portanto, projeta o status social como a sua segunda atividade. O professor confere ao sujeito contador um "status social" que não encontra no exercício da contabilidade, mas nega-se como professor e assim, declara que "é possível conciliar" as duas atividades como possibilidades de atualização de conhecimentos, de um outro status social e vantagens econômicas.

A conformação do ser professor como uma segunda atividade inviabiliza assumir uma real identidade de professor; logo, não caracteriza uma necessidade de formação pedagógica que supere sua formação inicial.

Porém, se o ensino superior de contabilidade não constitui instância de constituição da identidade própria do professor de contabilidade, se a sua formação reflete apenas apropriação de conhecimentos específicos caracterizados pela racionalidade técnica, então, faz-se urgente uma ruptura com as maneiras existentes em sua formação e na relação com o conhecimento. Ruptura essa expressa por um novo olhar sobre o trabalho e sobre a formação do professor de contabilidade.

Dessa forma, será possível desenvolver um processo ensino-aprendizagem significativo mediante a apropriação dos conhecimentos científicos, pois juntos, professores e alunos, pela mediação, serão capazes de revisitar o já presente e torná-lo ainda mais abrangente numa perspectiva de emancipação.

Outra questão que emerge na pesquisa é que os componentes da organização do trabalho do professor de contabilidade no ensino superior, ao se configurarem mediante as concepções dos professores sobre o processo ensino-aprendizagem, o aluno, a avaliação, a instituição universitária e o significado das funções do professor, acabam caracterizando e formatando um determinado 'modelo' de currículo.

O currículo modelado pelos professores de contabilidade reflete os diferentes conhecimentos e atividades desenvolvidos no processo ensino-aprendizagem, a seleção de conhecimento que constituem os conteúdos contábeis e também as experiências, ações e conhecimentos profissionais do professor e sua trajetória de vida.

É nesse momento do seu trabalho - a modelagem do currículo - que o professor de contabilidade pode configurar certa autonomia e criticidade no desenvolvimento do trabalho pedagógico. Conhecer essa dimensão do trabalho docente permite ao professor interferir, não apenas na aprendizagem dos alunos, mas também na forma como compreende a produção do seu trabalho. Processo que envolve superar o trabalho individual e buscar a organização do trabalho coletivo visando compreendê-lo na sua totalidade. Perspectiva essa que recompõe o seu ser político de autodeterminação, na construção do conhecimento, na participação do desenvolvimento do projeto político do curso, do currículo enfim, do exercício da sua prática pedagógica e de sua cidadania.

E por último faz-se necessário afirmar que este texto, construído com os referentes - os professores de contabilidade, os depoimentos, suas múltiplas falas - também se destina a outrem, difundindo partículas a partir de um jogo discursivo de referências. Esse texto construído já não é mais próprio, porque se constituiu da palavra alheia, da significação alheia 
e, em sendo alheio, liberado pelas muitas vozes e sentidos, ou seja, pela polissemia, e sendo do outro e para o outro, já requer o refazer do e no discurso produzido. Eis aí a possibilidade da práxis, da dialética. É do novo discurso, feito de intervenções, que se esperam novas possibilidades, não pela passagem consecutiva ao anterior, mas pela ruptura com o anterior.

Nesse movimento, recupera-se o entendimento de representação social como aquela que não reduz a realidade, mas antes como aquela que se complexifica no cotidiano e se expressa em múltiplos interesses. Assim, as palavras, os significados, os valores e as crenças produziram um discurso que também significa um lugar social.

O discurso é um jeito de expressar o pensar, e nesse jeito discursivo entre quem pesquisa e quem é pesquisado coexiste a enunciação que se remete para alguém. Tanto o jeito do discurso quanto esse outro a que se refere são construídos social e historicamente.

Ao propor estas discussões visualiza-se contribuir para a melhoria do ensino da contabilidade, porque esse estudo se configura como a primeira abordagem sobre a prática docente tomada em sua raiz pedagógica. Esse universo desvelado pelos depoimentos dos professores do ensino da contabilidade leva à convicção do desconforto de não querer fazer da maneira como está configurado. A possibilidade que emerge desse estudo é de se fazer diferente, mas sem saber a priori como será feito. Talvez quando alguém apontar o erro, as divergências, quando for considerado inadequado, quando estiver em desconformidade surjam os indícios das novas possibilidades, a partir da negação do feitio, do feito. Metamorfoses as quais é preciso estar atento, pois como já expresso "menor que meu sonho não posso ser" (BELL, 1984). Esse foi o ponto de partida, o processo de novas referências é ainda turvo e abre-se em constituição junto ao coletivo dos professores de contabilidade.

No conjunto de depoimentos recolhidos para esta pesquisa enfatiza-se, pela reconstrução significada e ressignificada, que o absurdo do mito de Sísifo construído não é de outrem, mas principiou em cada um de nós. Assim, como no mito de Sísifo, o trabalho do professor de contabilidade, como trabalho desprovido de uma epistemologia docente, é um trabalho que requer novos e contínuos estudos para superar a sua conformação. A marca que tem o contador na sociedade atual envolve o ressignificar de múltiplos contextos, anteriores e posteriores a essa intervenção. $O$ espaço de alienação, que cabe ao sujeito humano na constituição dialética de sua subjetividade impõe o escapar da homologia conceptual do imutável. Essas são as possibilidades que emergem no movimento cotidiano, na incompletude e na busca de nossa totalidade como sujeitos e professores.

\section{REFERÊNCIAS}

BELL, Lindolf. O código das águas. Ed. Global, São Paulo, 1984.

KUENZER, Acacia Zeneida. Para estudar o trabalho como princípio educativo na universidade: categorias teórico-metodológicas. Tese Concurso Professor Titular. UFPR, Curitiba, 1992.

MORIN, E. Articular os saberes. In.. ALVES, N. GARCIA R.L. (org.), O sentido da escola. Rio de Janeiro: DP\&A Editora, 2000.

SACRISTÁN, J. Gimeno. O currículo - uma reflexão sobre a prática. Porto Alegre: Artmed, 1998. 
SACRISTÁN, J.G. e GÓMEZ, A. P. Compreender e transformar o Ensino. Porto Alegre: Artmed. 1998.

SACRISTÁN, J.Gimeno. Consciência e ação sobre a prática como libertação profissional dos professores. In: NÓVOA, Antonio. (org). Profissão Professor. Porto: Porto Editora, 1995. 